\title{
BMJ Open Sexual harassment and assault among university students in Norway: a cross- sectional prevalence study
}

\author{
Børge Sivertsen, ${ }^{1,2,3}$ Morten Birkeland Nielsen, ${ }^{4,5}$ Ida E H Madsen, ${ }^{6}$ \\ Marit Knapstad, ${ }^{1,7}$ Kari Jussie Lønning, ${ }^{8,9}$ Mari Hysing ${ }^{5}$
}

To cite: Sivertsen B, Nielsen MB, Madsen IEH, et al. Sexual harassment and assault among university students in Norway: a cross-sectional prevalence study. BMJ Open 2019;9:e026993. doi:10.1136/ bmjopen-2018-026993

- Prepublication history for this paper is available online. To view these files, please visit the journal online (http://dx.doi. org/10.1136/bmjopen-2018026993).

Received 1 October 2018 Revised 15 May 2019 Accepted 20 May 2019
Check for updates

(C) Author(s) (or their employer(s)) 2019. Re-use permitted under CC BY-NC. No commercial re-use. See rights and permissions. Published by BMJ.

For numbered affiliations see end of article.

Correspondence to Professor Børge Sivertsen; borge.sivertsen@fhi.no

\section{ABSTRACT}

Objective The aim of the current study was to provide estimates of both overall and specific forms of sexual harassment among male and female college and university students.

Design and setting Data stem from a recent national student health survey from 2018 for higher education in Norway (the SHoT study (Students' Health and Wellbeing Study)).

Participants 50054 full-time students (69.1\% women) aged 18-35years participated, yielding a response rate of $31 \%$.

Main outcome measure Sexual harassment was defined according to Norwegian legal regulations, and was assessed by self-report on seven items covering verbal, non-verbal and physical sexual harassment. We also collected data on the timeframe and frequency of the sexual harassment, in addition to the formal position of the perpetrator of the harassment.

Results Lifetime sexual harassment was reported by $24.2 \%$ (women $31.3 \%$, men $8.0 \%$ ), while $16.7 \%$ (women $21.6 \%$, men $5.7 \%$ ) reported having been sexually harassed within the past year. The most common forms of lifetime (ever having experienced) sexual harassments were 'sexual expressions, suggestions or comments about your body' and 'unwanted touching, hugging or kissing' (both 15.4\%), while rape and rape attempt were reported by $3.4 \%$ and $2.1 \%$, respectively. Exposure to all forms of past-year sexual harassments was significantly more common among women and the youngest age cohorts. Fellow students committed the past-year sexual harassment in $18 \%-29 \%$ of the instances, while a university staff member was reported to have committed the harassment in $0.6 \%-4.6 \%$ of cases.

Conclusion Given the potential consequences suffered by those exposed to sexual harassment and assault, both the institutions and student welfare organisations should intensify their efforts to put the theme on the agenda and provide both legal and health services to victims of sexual harassment. The low response rate means that care should be taken in interpreting and generalising the findings to the whole student population.

\section{INTRODUCTION}

The \#MeToo movement has highlighted the challenge and impact of sexual harassment in most institutions and organisations,

\section{Strengths and limitations of this study}

- The SHoT2018 study (Students' Health and Wellbeing Study) is a national student health survey for higher education in Norway and included 50054 full-time students aged 18-35.

- Sexual harassment was defined according to Norwegian legal regulations, covering detailed data on verbal, non-verbal and physical sexual harassment, in addition to information on the timeframe and frequency of the sexual harassment and the formal position of the perpetrator of the harassment.

- Limitations of the study include the relatively low response rate in SHoT2018 (31\%).

including academia. Sexual harassment is formally defined as unwanted sex-related behaviours that are appraised by the recipient as offensive and that exceed one's coping resources or threaten one's well-being. This includes unwelcome verbal and non-verbal sexual behaviours, as well as undesired physical behaviours that the target finds difficult to cope with or to handle. ${ }^{1}$ When defined widely, as we do in the current paper, sexual harassment also includes sexual assault, rape attempt and rape. A range of negative consequences related to sexual harassment have been documented, with sexual harassment increasing the risk of both mental ${ }^{2}$ and somatic ${ }^{3}$ health problems. Sexually harassed students have also been shown to perform worse academically, ${ }^{4}$ as well as being more likely to engage in risky behaviours such as increased drug use, problematic drinking behaviours, sexual risk taking and sexual dysfunction. ${ }^{56}$

In a recent systematic review of the literature, Fedina $e t a l^{7}$ synthesised the prevalence estimates of sexual harassment in college samples based on 34 studies originating from the USA, published from 2000 to 2015. The authors concluded that while the prevalence rates varied greatly, mainly due to 
measurement and definitional differences, unwanted sexual contact was the most prevalent form of harassment, followed by rape or rape attempt. For example, for unwanted sexual contact (excluding rape or rape attempt), the majority of studies reported estimates of over $20 \%$ in college women, although the rates ranged widely from $1.8 \%$ to $34 \% .^{7}$ For male college students, the findings regarding unwanted sexual contact also varied considerably, from $4.8 \%{ }^{8}$ to $31 \% .^{9}$ In terms of rape, the prevalence findings for women ranged from $0.5 \%{ }^{10}$ to $8.4 \%,{ }^{11}$ while rates for attempted rape in women ranged from $1.1 \%{ }^{12}$ to $3.8 \% .^{13}$ The majority of the included studies focused predominantly on white, female undergraduate students. Also, the authors specifically called for studies specifying the timeframe in which the various sexual harassment occurred in order to better distinguish recent experiences happening in college from lifetime and childhood experiences. Moreover, the authors concluded that future studies should provide examples of unwanted sexual experiences when defining sexual harassment in order to better differentiate specific forms of sexual harassment. ${ }^{7}$ Recently, high prevalence rates of sexual harassment and violence have also been reported from European universities, ${ }^{14}{ }^{15}$ and a large study of $42000+$ women from 28 European Union states showed that one in five women had experienced sexual violence (although not limited to campuses). ${ }^{16}$ Previous Norwegian studies of sexual harassment are virtually non-existent, with two notable exceptions. Nielsen $e^{a l^{17}}$ found that $1 \%-2 \%$ of the Norwegian employees reported having been exposed to sexual harassment, assessed with a single item, during the last 6 months, and a small study of elite female athletes found that nearly half of them had experienced some form of lifetime sexual harassment or abuse, assessed by an 11-item scale. ${ }^{18}$

Based on these considerations, the aims of the current study were (1) to estimate the prevalence rates of both overall and specific forms of sexual harassment by providing brief examples, and also to differentiate between recent and lifetime experiences; (2) to explore possible age and gender differences across these measures; and (3) to examine who (fellow student, university staff or others) committed the sexual harassment acts. Data stem from a large national survey from 2018 in which all fulltime students under the age of 35 taking higher education in Norway were invited to participate.

\section{METHODS}

\section{Study design and setting}

The SHoT2018 study (Students' Health and Wellbeing Study) is a national student survey for higher education in Norway initiated by the three largest welfare organisations (Sammen (Bergen and surrounding area), SiT (Trondheim and surrounding area) and $\mathrm{SiO}$ (Oslo and Akershus)). The SHoT2018 was collected electronically through a web-based platform. Details of the study have been published elsewhere, ${ }^{19}$ but in short the SHoT2018 was conducted between 6 February and 5 April 2018, and invited all full-time Norwegian students pursuing higher education (both in Norway and abroad).

\section{Participants}

All full-time Norwegian students aged between 18 and 35 taking higher education (both in Norway and abroad) received both an email and SMS (short message service) text invitation to take part in the study. For the SHoT2018 study, 162512 students fulfilled the inclusion criteria, of whom 50054 students completed the online questionnaires, yielding a response rate of $30.8 \%$.

\section{Instruments}

Demographic information (SHoT2018)

All participants indicated their sex and age, and participants were also asked about their household status (coded as 'living alone' vs 'living with others') as well as their relationship status (coded as 'single' vs 'married'/ 'partner' or 'girl-/boyfriend'). Finally, participants were categorised as an immigrant if either the student or his/her parents were born outside Norway.

\section{Sexual harassment}

In the current study sexual harassment was assessed using a seven-item self-report instrument covering three forms of sexual harassment, also corresponding to the legal definition of sexual harassment in Norway : (1) verbal harassment (sexual expressions and suggestions, comments about body, appearance or private life); (2) non-verbal harassment (2a: close eye or body movements; 2b: viewing sexual images (including digital); 2c: indecent exposure); and (3) physical harassment (3a: unwanted touching, hugging or kissing; 3b: rape attempt; 3c: rape). First, the students were given the following, common definition of sexual harassment: "unwanted sex-related behaviours that are appraised by the recipient as offensive or bothersome'.

For each of the seven forms of harassment, the respondents indicated who conducted the harassment (fellow student, employed at the educational institution or others), when the harassment was experienced ('past month', 'past year', 'more than a year ago, but after entering college/university, and 'before entering college/ university') and how many times he/she had experienced sexual harassment. In the current study, we define a 'recent' event as an episode having occurred within the past 12 months (the first two response options). Box 1 details the exact wording used in the questionnaire.

\section{Statistics}

IBM SPSS V.25 for Mac was used for all analyses.

Negative binomial regression analyses were used to examine gender differences in the prevalence of sexual harassment forms across age groups. Negative binomial regressions (producing incidence rate ratios (IRR)) were used rather than the more commonly used logistic regressions (producing OR), as ORs tend to overstate an effect size compared with IRRs for high frequency outcomes (in 
Box 1 Sexual harassment questionnaire used in the SHoT2018 study (Students' Health and Wellbeing Study).

Sexual harassment is defined as unwanted sexual awareness that is offensive and troublesome.

Please indicate if you have been exposed to any of the following forms of sexual harassment?

Verbal harassment.

$\square$ Sexual expressions and suggestions, comments about your body, appearance or private life.

Non-verbal harassment.

$\square$ Intrusive eye or body movements.

$\square$ Viewing/sending sexual images (including digital).

$\square$ Indecent exposure.

Physical harassment.

$\square$ Unwanted touching, hugging or kissing.

$\square$ Rape attempt.

$\square$ Rape.

Repeat for each harassment form:

Who were you sexually harassed by?

(One or more ticks.)

$\square$ Fellow student.

$\square$ Staff at the educational institution.

$\square$ Other.

When were you last sexually harassed?

$\square$ Past month.

$\square$ Past year.

$\square$ More than a year ago, but after entering college/university.

$\square$ Before entering college/university.

How many times have you experienced being sexually harassed?

this case relevant for some forms of sexual harassment). ${ }^{20}$ Missing values were handled using listwise deletion.

\section{Patient and public involvement}

The planning and design of the study were initiated and governed by the student welfare organisations, which included deciding the inclusion and exclusion criteria, and selecting potential research questions and instruments. Students were not involved in the actual collection of data, although recruitment was conducted in close collaboration with all the student welfare organisations in Norway. The results will be disseminated to the study participants via outlets of the student welfare organisations and educational institutions, with newsletters highlighting the main findings being made available to all students. Popular summaries of results and interpretations with interest for a wider audience will be disseminated in appropriate outlets (eg, the web pages of educational institutions and the Norwegian Institute of Public Health (NIPH)).

\section{RESULTS}

\section{Descriptive characteristics and representativeness}

Compared with all invited students $(58.1 \%$ women $(\mathrm{n}=93267)$ and $41.9 \%$ men $(\mathrm{n}=67558))$, the current sample included a larger proportion of women $(69.1 \%)$ than men $(30.9 \%)$. The mean age was $23.2(\mathrm{SD}=3.3)$, and the age distribution of participating students (18-20years $(18 \%, \mathrm{n}=8832), 21-22$ years $(31 \%, \mathrm{n}=15471), 23-25$ years $(32 \%, \mathrm{n}=15902), \quad 26-28$ years $(12 \%, \mathrm{n}=5710)$ and $29-35$ years $(7 \%, \mathrm{n}=3427))$ was almost identical to that of all invited students (18-20years $(18 \%, \mathrm{n}=28996)$, 21-22 years $(31 \%, \quad \mathrm{n}=49731), \quad 23-25$ years $\quad(32 \%$, $\mathrm{n}=51714), 26-28$ years $(12 \%, \mathrm{n}=19901)$ and $29-35$ years $(6 \%, \mathrm{n}=10216))$. In terms of accommodation status, $19.3 \%$ reported living alone, while $49.9 \%$ reported being single. Eight per cent of the sample were immigrants, defined as either the student or his/her parents being born outside Norway.

\section{Prevalence of sexual harassment}

Lifetime sexual harassment was reported by $24.2 \%$ of the students, and $16.7 \%$ reported having been sexually harassed within the past year. Women reported substantially more sexual harassment than men (lifetime: $31.3 \%$ vs $8.0 \%$, IRR $=3.9,95 \%$ CI 3.7 to 4.1 ). A similar gender effect was also observed for past-year sexual harassment $(21.6 \%$ vs $5.7 \%$, IRR $=3.8,95 \%$ CI 3.5 to 4.0; see table 1 for details). The most common forms of lifetime sexual harassment were sexual expressions and suggestions, comments about your body, appearance or private life, and unwanted touching, hugging or kissing, which both were reported by $15.4 \%$ of the students. Intrusive eye or body movements were also common (11.4\%), whereas viewing/sending sexual images $(3.7 \%)$ and indecent exposure $(1.7 \%)$ were less frequently reported. Rape and rape attempt were reported by $3.4 \%$ and $2.1 \%$, respectively. As detailed in table 1, large gender differences were observed across all variables.

Figure 1 depicts students' detailed responses when he/ she were last sexually harassed, showing that, for example, $17.1 \%$ and $3.3 \%$ of women and men, respectively, had been verbally harassed since entering college/university. At a similar level, $15.2 \%$ and $4.4 \%$ of women and men, respectively, reported unwanted touching, hugging or kissing since they started on the college/university studies (see figure 1 for more details).

As outlined in box 1 and further detailed in figure 2, all forms of sexual harassment experienced during the past year were significantly more common in the youngest age cohort. For example, while $19.4 \%$ of those aged 18-20years reported any form of sexual harassment during the last 12 months, the corresponding proportion among those in the older cohort was $18.1 \%$ (21-22 years), $16.4 \%$ (23-25 years), $14.3 \%$ (26-28 years) and $9.3 \%$ (29-35years). Similar age effects were observed across most forms of past-year sexual harassment, with a few exceptions (eg, indecent exposure).

\section{Number of occurrences of sexual harassment}

As detailed in figure 3, the majority of those students reporting lifetime sexual harassment reported multiple occurrences across all forms of harassment, except rape, for which the majority of both women $(68.2 \%)$ and men $(66.1 \%)$ reporting rape had experienced this once. 


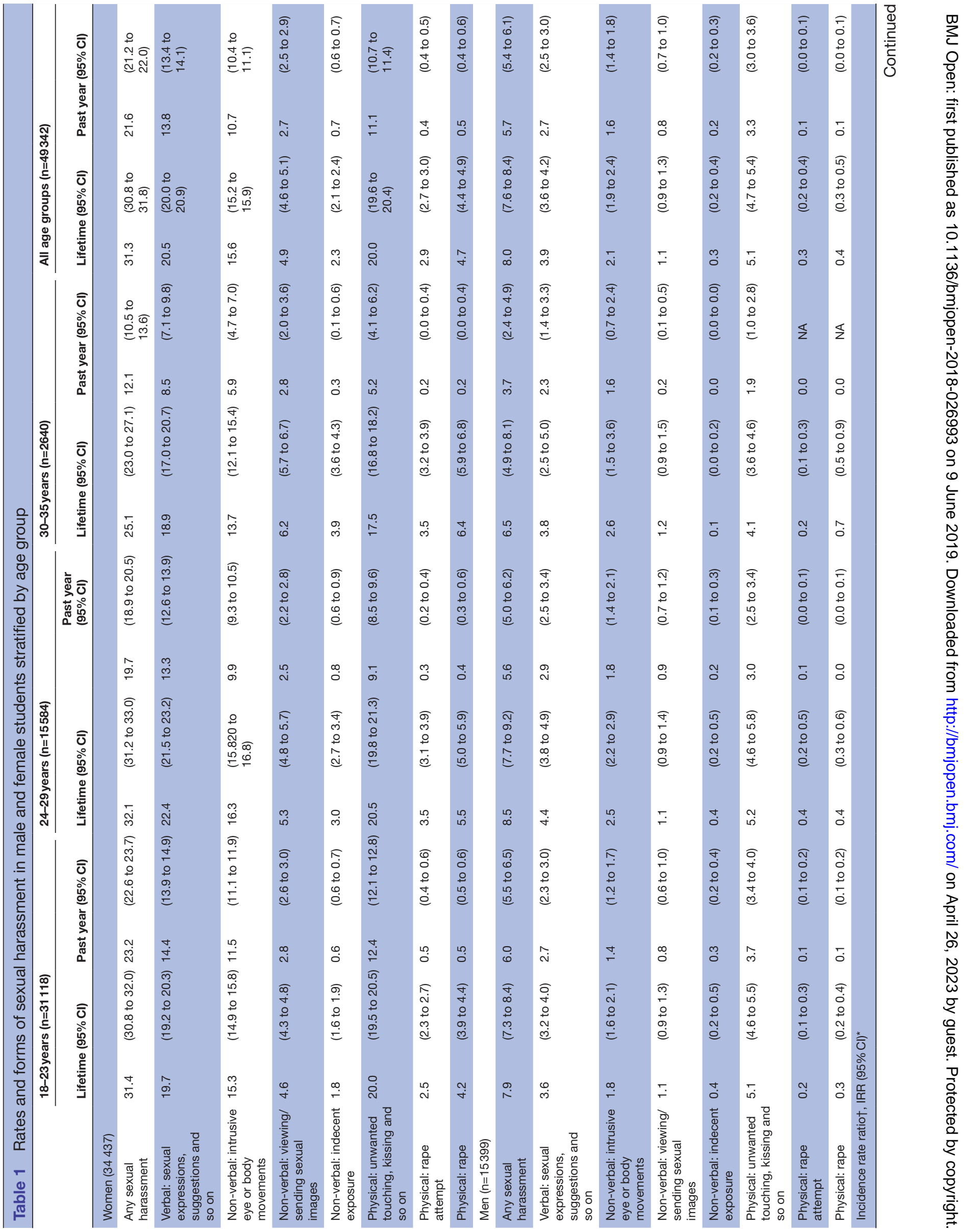




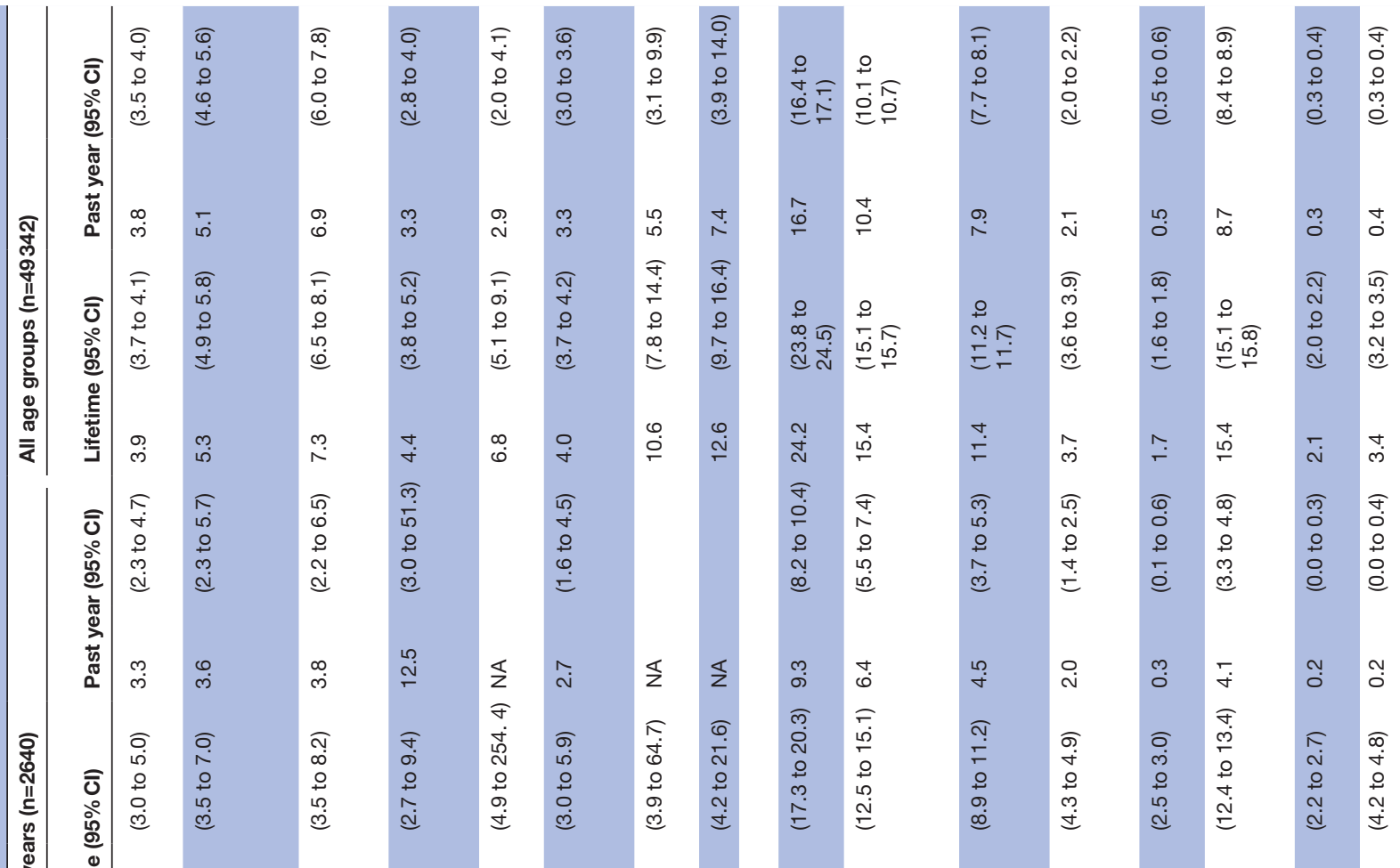




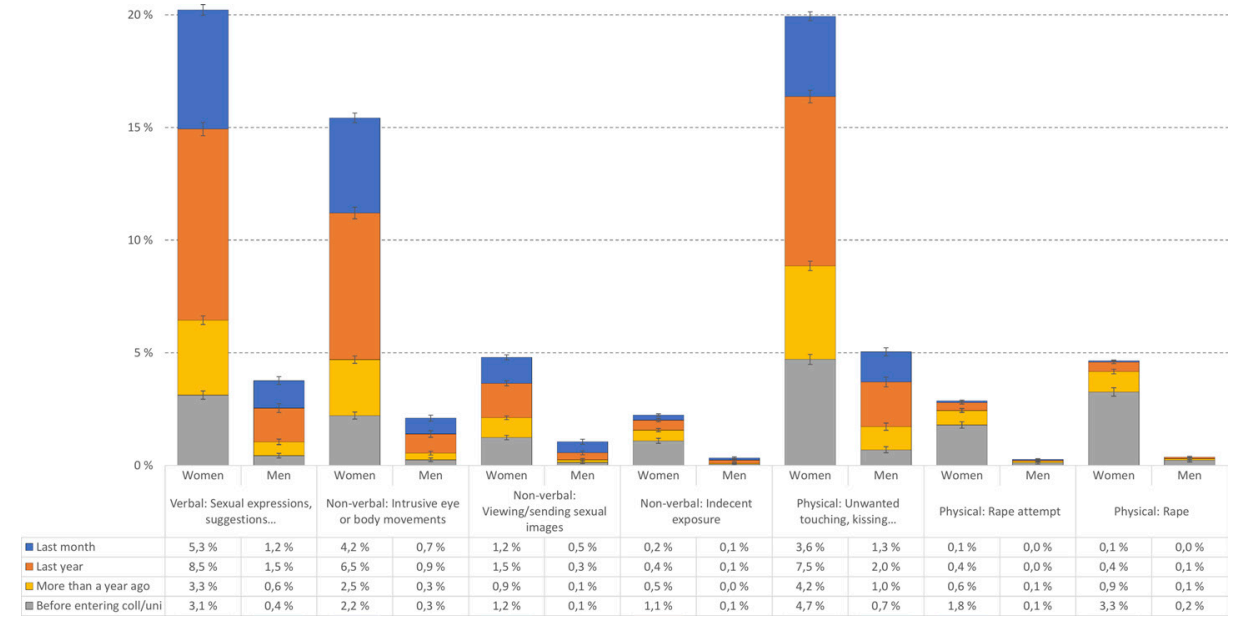

Figure 1 Detailed timeframe of sexual harassment forms stratified by sex. Error bars represent $95 \% \mathrm{Cl}$.

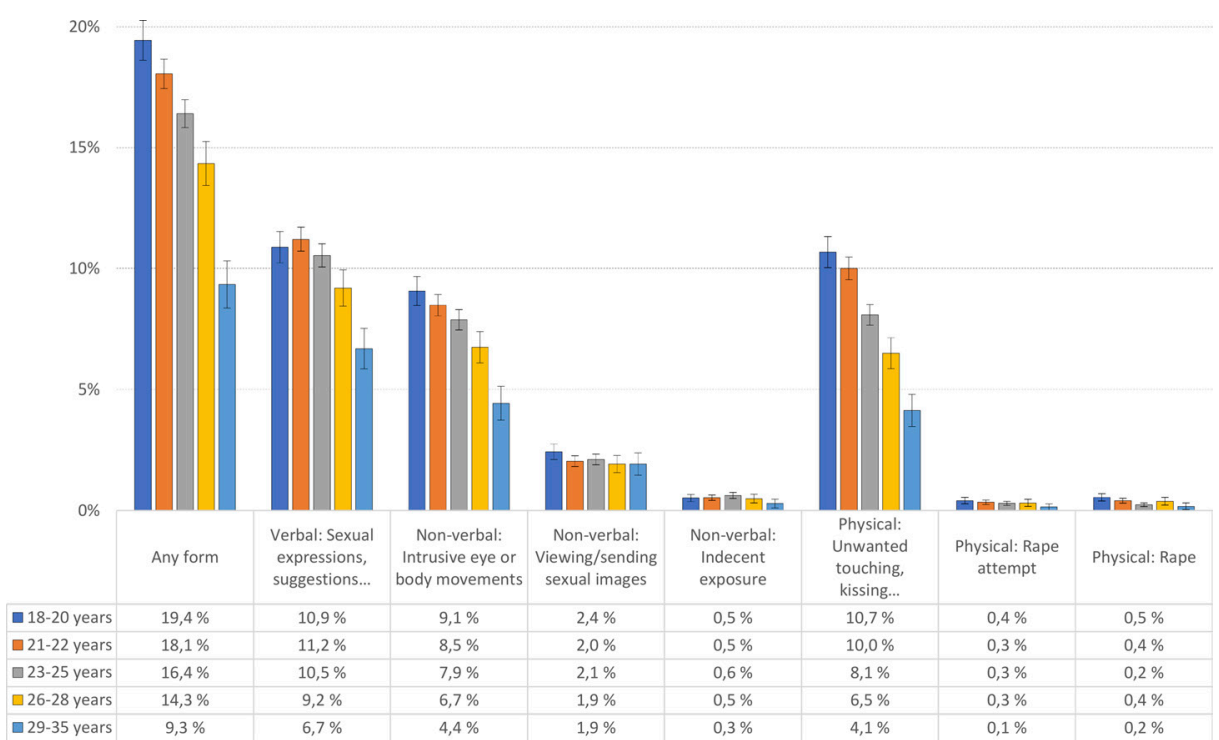

Figure 2 Proportion of students across age groups reporting sexual harassment in the past year. Error bars represent $95 \% \mathrm{Cl}$.

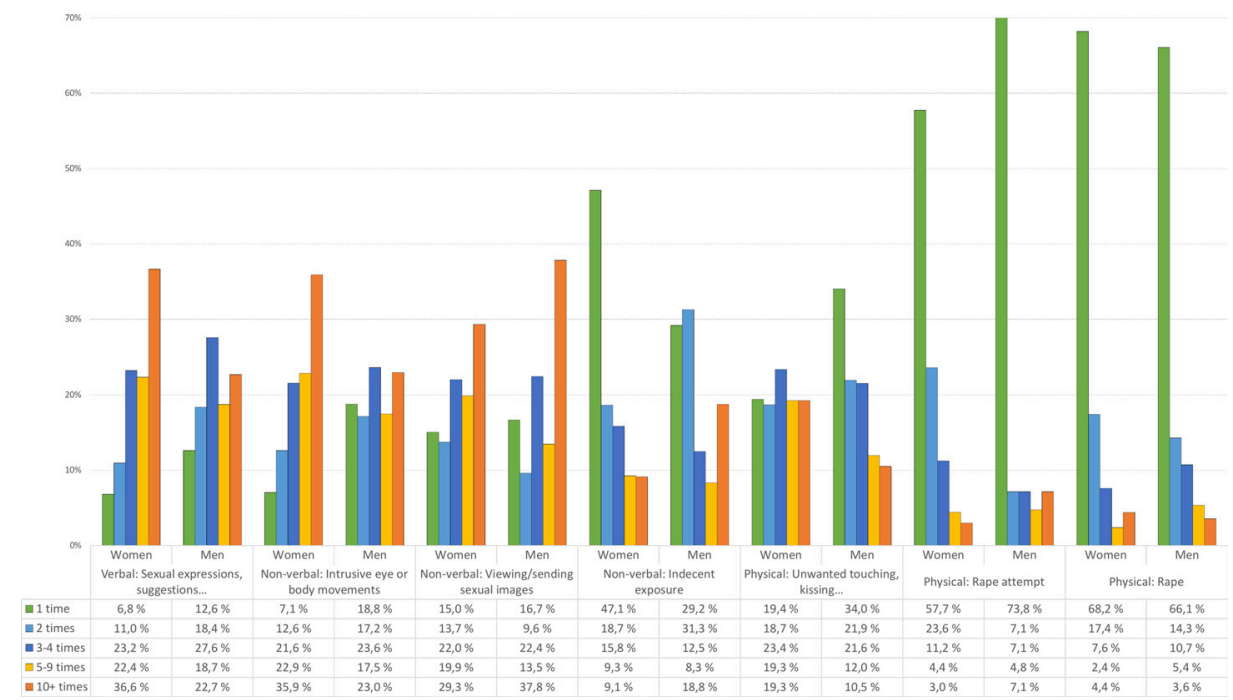

Figure 3 Number of lifetime occurrences among students having reported harassment stratified by gender. 


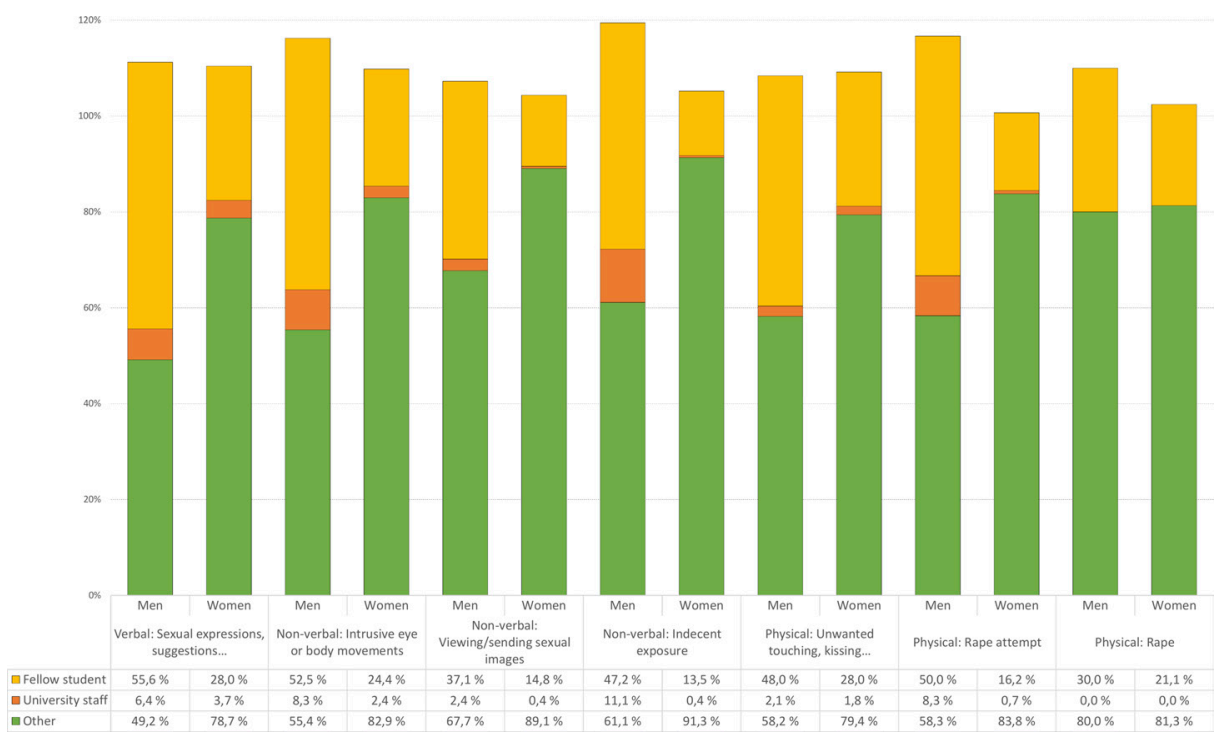

Among those reporting sexual verbal harassment, a larger proportion of women $(36.1 \%)$ than men $(22.7 \%)$ reported repeated verbal harassment (defined as more than 10 times). This gender difference was also present for intrusive eye or body movements, but not for the other harassment forms (see figure 3 for details).

\section{Person reported as perpetrators of the sexual harassment}

The large majority of past-year sexual harassment acts (across all forms: $77 \%-86 \%$ ) were conducted by someone outside of the university (neither a fellow student nor university staff member). Overall, fellow students committed the harassment in 18\%-29\% of the cases, whereas a university staff member was reported to have conducted the harassment in $0.6 \%-$ $4.6 \%$ of the instances. As displayed in figure 4, among those students having reported each harassment form within the past year, a larger proportion of men compared with women reported being sexually harassed by a fellow student. A correspondingly larger proportion of women reported being sexually harassed by someone outside of the university, compared with men. There was also a trend that a larger proportion of men reported being harassed by a university staff member across most harassment forms $(p<0.001)$, except for physical harassment.

\section{DISCUSSION}

\section{Statement of principal findings}

This large national survey from 2018, inviting all full-time Norwegian university and college students aged 18-35, suggests that sexual harassment among Norwegian college and university students is prevalent. Almost one in four students $(24.2 \%)$ reported lifetime sexual harassment of some form, while one in six students $(16.7 \%)$ reported being sexually harassed during the past year. Women reported more lifetime and recent exposure to sexual harassment across all subtypes included in the survey, but also a substantial proportion of men reported exposure to sexual harassment. Younger students reported significantly more sexual harassment the past year than older students, and the majority of those being harassed reported multiple occurrences across all forms of harassment (except rape). The majority of recent harassment acts were committed by someone outside of the university setting, while a fellow student and university staff member committed the harassment in $18 \%-29 \%$ and $0.6 \%-4.6 \%$, respectively, of the instances.

\section{Strengths and weaknesses in relation to other studies, discussing important differences in results}

Being one of the first studies of this magnitude on the prevalence of sexual harassment conducted after the \#MeToo movement, the current study provides new evidence that sexual harassment indeed is a substantial problem also in college and university settings. The current estimates of sexual harassment are comparable with the review by Fedina et $a l,{ }^{7}$ who synthesised research in the field from the last 15 years, concluding that although prevalence rates vary, they all indicate that a substantial number of college and university students experience sexual harassment. In line with that review, as well as estimates from European universities, ${ }^{14}{ }^{15}$ we also found that unwanted sexual contact and verbal sexual harassment were the most prevalent forms, both being reported by approximately $15 \%$ of the students $(20 \%-21 \%$ of women and $4 \%-5 \%$ of men). In terms of lifetime rape and rape attempt, this was reported by $3.4 \%$ and $2.1 \%$, respectively, whereas the past year prevalences were around $0.4 \%$. And while the results showed that most of the rape and rape attempts occurred before entering college/university, the majority of those students reporting the other five sexual 
harassment forms had experienced this after they started their college/university studies. The increased focus and attention following \#MeToo may have impacted some of the respondents' willingness to describe taboo experiences, including sexual harassment. As such, it is difficult to outline possible trends or compare with prevalence rates from previous studies in academic settings. Similarly, differences in the used operationalisations and sampling procedures make it difficult to directly compare our findings with earlier studies. Some of the discrepancies may also be attributed to cultural characteristics.

Young women were especially at high risk, a finding that is also in accordance with previous studies specifically addressing this group. ${ }^{21}{ }^{22}$ Male victims of sexual harassment have been less studied, and although sexual harassment against women is a much more prevalent issue the present results are in accordance with previous studies that report less, but still a substantial rate of sexual harassment among male students. ${ }^{23}$ The reasons for not reporting sexual harassment or abuse may be the same for women and men (eg, intimidation, shame, fear of not being believed), but there may also be other reasons for previous under-reports of male victims of sexual harassment, such as cultural attitudes about manliness, masculinity and so on. It should also be noted that previous research has shown that women and men differ in the perceptions of sexual harassment, as men has a higher threshold for labelling an experience as sexually harassing. ${ }^{24}$ Regarding the observed age difference, this might partly be explained by recall bias, differences in perceptions of sexual harassment between older and younger students, and/or a healthy survivor effect where the (severely) harassed drop out of university in a young age. How much these mechanisms affect the prevalence is difficult to quantify, although differences in recall bias are likely to affect the past year prevalence to a lesser degree than lifetime.

A small percentage of the reported sexual harassments were from university staff members. Even so the current study shows that there are still many students who experience some form of sexual harassment from a person in power or in a trusted position. This is especially worrisome and may need to be specifically addressed in preventive programmes.

The increase in digital communication has been paralleled by an increased focus on sexual harassment through sending or viewing offensive pictures (eg, people sending 'nude/dick pics'). ${ }^{25}$ Very few studies have investigated this form of sexual harassment, and the present results document that, although it is among the less frequent types of sexual harassment, it is still reported by $3.7 \%$ of the students. The rate was relatively higher 'the past month' and 'the past year', which may indicate that it is a growing problem. However, trend studies over time are needed to further shed light on this.

Compared with findings from work-life populations, where most studies include only harassment conducted in the workplace, the present findings are not dissimilar to those reported recently from a Danish union survey. ${ }^{26}$ This survey found that, when asked about specific situations of unwanted sexual attention, $26.5 \%$ of women and $25.7 \%$ of men had experienced some sort of unwanted sexual attention in the workplace during the past 12 months. However, most larger scale studies have included only crude overall single-item assessments of exposure to sexual harassment, which yield much lower prevalence estimates. In the union survey, only $2.1 \%$ of women and $0.3 \%$ of men reported being exposed to sexual harassment during the past 12 months when using such a single-item measure. Applying the sexual experiences questionnaire, a questionnaire which includes items regarding specific types of harassment similar to those included in the present study, Fitzgerald $e t a t^{27}$ reported prevalences of more than $70 \%$ for women and $30 \%$ for men from a US military sample in 1999. However, there is a need for more nationally representative studies using questionnaires assessing specific types of sexually harassing situations to further elucidate the magnitude of this problem within the workforce.

\section{Meaning of the study: possible explanations and implications} for clinicians and policymakers

The study has some important clinical implications, as there is substantial evidence showing that victims of sexual assault are more likely to suffer from short-term and long-term health problems. ${ }^{23}$ Our finding showing that the youngest female students are particularly at risk of being sexually harassed is disturbing. The higher risk of harassment among female students is especially problematic as previous research has shown that women display stronger reactions to sexual harassment than men. ${ }^{28}$ So although many universities and student welfare organisations run awareness campaigns that focus on preventing sexual harassment on campuses, the results of the present study suggest more should be done. Colleges and universities have a unique opportunity to reach many young adults. Future studies should include information on the situations where the harassment occurs to better tailor interventions. There is still limited empirical evidence for the effectiveness of universal prevention programmes, ${ }^{29}$ although there are interventions with promising results. ${ }^{30} 31$ Our finding that the youngest students were more at risk than older students suggests that the interventions should target new students specifically. The high prevalence of sexual harassment also has implications for victim services, which include providing both appropriate treatment and legal services. While prevalence rates and forms of sexual harassment may differ from campus to campus, prevention, intervention and victim service strategies require a detailed overview of the specific needs for each campus population.

Research from work-life settings has shown that while training of employees in the forms of antiharassment courses is important, additional measures are needed. To minimise harassment, organisations and institutions should nurture a common culture that rejects harassment 
and where all students and employees are equally entitled to a work environment without harassment. Supporting the effectiveness of an 'anti-harassment' culture, research findings show that a strong climate for conflict management in organisations is associated with lower prevalence of harassment, while also protecting against the effects of harassment when it occurs. ${ }^{32}$

\section{Strengths and weaknesses of the study}

The most important limitation of the present study is the relatively modest response rate of $31 \%$, with little information about the characteristics of non-participants beyond age and gender distribution. Selective participation could bias the prevalences observed to the extent the selection was correlated with reports of sexual harassment. On one hand, it has been shown that non-participants of health surveys in general have poorer health than participants, ${ }^{33}$ and as those exposed to sexual harassment have more mental ${ }^{2}$ and somatic ${ }^{3}$ health problems the current results may represent an underestimation of the true prevalence in the target population. On the other hand, people are in general more prone to participate in a survey if the topic is relevant to them personally, ${ }^{34}$ and as the information material of the SHoT2018 study focused much on 'how the students really are and feel', one may speculate if this would lead to a higher participation rate of individuals who felt that the topic was of particular relevance to them.

As response rates are particularly important in prevalence studies, care should be taken when generalising the current findings to the whole student population. Rather, it may be more appropriate to emphasise the relative differences between men and women, as well as different age cohorts found in the current study, as these estimates are less prone to selection bias. Related to this is the $69 \%$ female composition of the sample, which may represent a bias for the overall estimates, as women are far more likely to report harassments compared with men. Also, this problem was mitigated by examining findings separately for women and men. It is possible that the use of a web-based survey approach contributed to the modest response rate, as electronic platforms typically yield lower overall participation rates when compared with traditional postal mail approaches, such as paper-based surveys or face-to-face interviews. ${ }^{35}$ Another limitation is that we did not use a validated instrument when assessing sexual harassment, which would have been preferable and make comparisons across studies easier. Rather, we designed a new assessment battery, carefully following the content of the Norwegian legal regulations, which also corresponds well with the formal scientific definition of sexual harassment. ${ }^{1}$ The main rationale for making a new instrument was due to recent recommendations in the review by Fedina $e t a l^{7}$ where the authors specifically called for studies specifying the timeframe in which the sexual harassment occurred and to provide brief examples of unwanted sexual experiences when defining sexual harassment. A final limitation is that we do not know the extent of missing data, as the questionnaire was designed to only indicate the presence of each harassment form, and not the absence. As such, although we consider it most likely that a missing answer is an indication of not having experienced that particular sexual harassment, missing answer may also mean that (1) the participant may not want to answer that particular item, (2) the participant does not remember it, or (3) the data may be missing at random, for example, not related to sexual harassment.

The most important study strengths include the very large and heterogeneous sample, as nearly all previous studies in this field focused on white, female, young undergraduate students. ${ }^{7}$ Also, notwithstanding being newly developed, the included sexual harassment instrument allowed us to explore more detailed information than previously assessed.

\section{Author affiliations}

${ }^{1}$ Department of Health Promotion, Norwegian Institute of Public Health, Bergen, Norway

${ }^{2}$ Department of Research and Innovation, Helse Fonna HF, Haugesund, Norway ${ }^{3}$ Department of Mental Health, Norwegian University of Science and Technology, Trondheim, Norway

${ }^{4}$ National Institute of Occupational Health, 0slo, Norway

${ }^{5}$ Department of Psychosocial Science, University of Bergen, Bergen, Norway

${ }^{6}$ National Research Centre for the Working Environment, Copenhagen, Denmark

${ }^{7}$ Department of Clinical Psychology, University of Bergen, Bergen, Norway

${ }^{8}$ Vestre Viken HF, Drammen, Norway

${ }^{9}$ Student Welfare Organisation of Oslo and Akershus, Oslo, Norway

Acknowledgements We wish to thank all participating students, as well as the three largest student organisations in Norway (SiO, Sammen and SiT), who initiated and designed the SHOT studies.

Contributors BS and $\mathrm{MH}$ drafted the manuscript and conducted the statistical analyses. BS and KJL were responsible for conception and design of the study, and KJL obtained funding. MN, IEHM, MK and KJL gave critical revision of the manuscript for important intellectual content. All authors have approved the manuscript being submitted.

Funding SHoT2018 has received funding from the Norwegian Ministry of Education and Research (2017) and the Norwegian Ministry of Health and Care Services (2016).

Competing interests None declared.

Patient consent for publication Obtained.

Ethics approval The SHoT2018 study was approved by the Regional Committee for Medical and Health Research Ethics in Western Norway (no 2017/1176), and electronic informed consent was obtained after complete description of the study to the participants.

Provenance and peer review Not commissioned; externally peer reviewed.

Data sharing statement The SHoT2018 data set is administrated by the NIPH. Approval from a Norwegian regional committee for medical and health research ethics (https://helseforskning.etikkom.no) is a prerequirement.

Open access This is an open access article distributed in accordance with the Creative Commons Attribution Non Commercial (CC BY-NC 4.0) license, which permits others to distribute, remix, adapt, build upon this work non-commercially, and license their derivative works on different terms, provided the original work is properly cited, appropriate credit is given, any changes made indicated, and the use is non-commercial. See: http://creativecommons.org/licenses/by-nc/4.0/.

\section{REFERENCES}

1. Fitzgerald LF, Swan S. But was it really sexual harassment?: Legal, behavioral, and psychological definitions of the workplace victimization of women. In: O'Donohue W, ed. Sexual harassment: 
Theory, research, and treatment. Needham Heights, MA, US: Allyn \& Bacon, 1997:5-28.

2. Kaura SA, Lohman BJ. Dating violence victimization, relationship satisfaction, mental health problems, and acceptability of violence: a comparison of men and women. $J$ Fam Violence 2007;22:367-81.

3. Campbell R, Sefl T, Ahrens CE. The physical health consequences of rape: assessing survivors' somatic symptoms in a racially diverse population. Women's Studies Quarterly 2003:31:90-104.

4. Jordan CE, Combs JL, Smith GT. An Exploration of Sexual Victimization and Academic Performance Among College Women. Trauma Violence Abuse 2014;15:191-200.

5. Turchik JA, Hassija CM. Female Sexual Victimization Among College Students: Assault Severity, Health Risk Behaviors, and Sexual Functioning. J Interpers Violence 2014;29:2439-57.

6. Gidycz CA, Orchowski LM, King CR, et al. Sexual victimization and health-risk behaviors: a prospective analysis of college women. $J$ Interpers Violence 2008;23:744-63.

7. Fedina L, Holmes JL, Backes BL. Campus Sexual Assault: a systematic review of prevalence research from 2000 to 2015. Trauma Violence Abuse 2018;19:76-93.

8. Flack WF, Caron ML, Leinen SJ, et al. "The red zone": temporal risk for unwanted sex among college students. $J$ Interpers Violence 2008;23:1177-96.

9. Walsh WA, Banyard VL, Moynihan MM, et al. Disclosure and service use on a college campus after an unwanted sexual experience. $J$ Trauma Dissociation 2010;11:134-51.

10. Hines DA, Armstrong JL, Reed KP, et al. Gender differences in sexual assault victimization among college students. Violence Vict 2012;27:922-40.

11. McCauley J, Ruggiero KJ, Resnick HS, et al. Forcible, drugfacilitated, and incapacitated rape in relation to substance use problems: results from a national sample of college women. Addict Behav 2009;34:458-62.

12. Fisher BS, Cullen FT, Turner MG. The sexual victimization of college women. https:// www.ncjrs.gov/pdffiles1/nij/182369.pdf2000.

13. Humphrey JA, White JW. Women's vulnerability to sexual assault from adolescence to young adulthood. $J$ Adolesc Health 2000;27:419-24.

14. Romito P, Cedolin C, Bastiani F, et al. Sexual harassment and menstrual disorders among Italian university women: A cross-sectional observational study. Scand J Public Health 2017;45:528-35.

15. List K. Gender-Based violence against Female Students in European University Settings. International Annals of Criminology 2017;55:172-88.

16. European Union Agency for Fundamental Rights. Violence against women: an EU-wide survey. Main results report 2014.

17. Nielsen MB, Bjørkelo B, Notelaers G, et al. Sexual Harassment: Prevalence, Outcomes, and Gender Differences Assessed by Three Different Estimation Methods. J Aggress Maltreat Trauma 2010;19:252-74.
18. Fasting K, Brackenridge C, Sundgot-Borgen J. Experiences of sexual harassment and abuse among Norwegian elite female athletes and nonathletes. Res Q Exerc Sport 2003;74:84-97.

19. Sivertsen B, Råkil H, Munkvik E, et al. Cohort profile: The SHoTstudy, a national health and wellbeing survey of Norwegian university students. BMJ Open in press.

20. Davies HT, Crombie IK, Tavakoli M. When can odds ratios mislead? BMJ 1998;316:989-91.

21. Conley AH, Overstreet CM, Hawn SE, et al. Prevalence and predictors of sexual assault among a college sample. J Am Coll Health 2017;65:41-9.

22. Kimble M, Neacsiu AD, Flack WF, et al. Risk of unwanted sex for college women: evidence for a red zone. J Am Coll Health 2008;57:331-8.

23. Rosenthal MN, Smidt AM, Freyd JJ. Still Second class: sexual Harassment of Graduate Students. Psychol Women Quart 2016;40:364-77.

24. Einarsen S, Sørum D. Colleague or sex object? A cross-cultura study of sexual harassment in the workplace). Nordisk Sexologi 1996;14:17-33.

25. Cloos K, Turkewitz J. Hundreds of Nude Photos Jolt Colorado School. The New York Times 2015.

26. HK. Under overfladen [Under the surface]. 2017.

27. Fitzgerald LF, Magley VJ, Drasgow F, et al. Measuring Sexual Harassment in the Military: the Sexual Experiences Questionnaire (SEQ-DoD). Military Psychology 1999;11:243-63.

28. Nielsen MB, Einarsen S. Prospective relationships between workplace sexual harassment and psychological distress. Occup Med 2012;62:226-8.

29. Morrison S, Jennifer Hardison J, Mathew A, et al. An evidencebased review of sexual assault preventive intervention programs. Washington, DC: Department of Justice: Department of Justice, 2004.

30. Salazar LF, Vivolo-Kantor A, Hardin J, et al. A web-based sexual violence bystander intervention for male college students: randomized controlled trial. J Med Internet Res 2014;16:e203

31. Senn CY, Eliasziw M, Barata PC, et al. Efficacy of a sexual assault resistance program for university women. $N$ Engl $J$ Med 2015;372:2326-35

32. Einarsen S, Skogstad A, Rørvik E, et al. Climate for conflict management, exposure to workplace bullying and work engagement: a moderated mediation analysis. The International Journal of Human Resource Management 2018;29:549-70.

33. Knudsen AK, Hotopf M, Skogen JC, et al. The health status of nonparticipants in a population-based health study: the Hordaland Health Study. Am J Epidemiol 2010;172:1306-14.

34. Edwards PJ, Roberts I, Clarke MJ, et al. Methods to increase response to postal and electronic questionnaires. Cochrane Database Syst Rev 2009;3:MR000008.

35. Dykema J, Stevenson J, Klein L, et al. Effects of E-Mailed versus mailed invitations and incentives on response rates, data quality, and costs in a Web Survey of University Faculty. Soc Sci Comput Rev 2013;31:359-70. 